\title{
KIT NP_000213.1:p.S840I
}

National Cancer Institute

\section{Source}

National Cancer Institute. KIT NP 000213.1:p.S840I. NCI Thesaurus. Code C155716.

A change in the amino acid residue at position 840 in the mast/stem cell growth factor receptor Kit protein where serine has been replaced by isoleucine. 